\title{
Large-Scale Welding Process Simulation by GPU Parallelized Computing
}

\author{
High-fidelity prediction of welding distortion and residual stresses \\ were realized by a novel 3D explicit FEM
}

\author{
BY H. HUANG, J. CHEN, Z. FENG, H.-P. WANG, W. CAI, AND B. E. CARLSON
}

\begin{abstract}
The computational design of industrially relevant welded structures is extremely time consuming due to coupled physics and high nonlinearity. Previously, most welding distortion and residual stress simulations have been limited to small coupons and reduced order (from three-dimensional [3D] to two-dimensional [2D]), or inherent strain approximations were used for large structures. In this current study, an explicit finite element code based on a graphics processing unit was utilized to perform 3D transient thermomechanical simulation of structural components during welding. Laser brazing of aluminum alloy panels as representative of automotive manufacturing scenarios was simulated to predict out-of-plane distortion under different clamping conditions. The predicted deformation pattern and magnitude were validated by laser scanning data of physical assemblies. In addition, the code was used to investigate residual stresses developed during multipass arc welding of a nuclear industry pressurizer surge nozzle and subsequent welding repair where a $3 D$ simulation was necessary. Taking the experimental data as reference, the $3 \mathrm{D}$ model predicted better residual stress distribution than a typical $2 \mathrm{D}$ asymmetrical model. Stress evolution in welding repair was also presented and discussed in this study. The efficient numerical model made it feasible to use integrated computational welding engineering to simulate welding processes for large-scale structures.
\end{abstract}

\section{KEYWORDS}

- Welding Simulation • Finite Element Method (FEM)

- Welding Distortion • Residual Stresses

- Graphics Processing Unit (GPU) Parallel Computing

- Laser Brazing

\section{Introduction}

Fusion welding generally introduces a significant amount of heat to joints, which results in thermal distortion and residual stresses that negatively affect dimensional and structural integrity. To join aluminum or steel panels with aesthetic quality, laser brazing is widely used in the mass production of vehicle bodies (Refs. 1, 2). In the laser brazing process, a filler metal is melted under laser irradiation and deposited between two workpieces, which then solidify and form a joint. Due to relatively thin sheet metal thicknesses and fast heating-cooling rates, out-of-plane distortion can occur during welding and brazing (Ref. 3), often requiring additional corrective actions. For example, buckling distortion can be induced by thermal stresses, which were studied by Tsai et al. (Ref. 4) as well as Yang and Dong (Ref. 5) with the corresponding mitigation methods being proposed. $\mathrm{Nu}-$ merical modeling can be used to evaluate panel distortion under various heat inputs and clamping conditions, thereby saving time and cost on experimental trials. The shell model (Ref. 6) and a hybrid solid/shell (Ref. 7) element technique were proposed for modeling the laser brazes/welds to accelerate the meshing and computing processes. However, three-dimensional (3D) solid element models are generally considered to have better accuracy since they discretize the local fusion zone in all directions without compromising the thickness direction.

While welding/brazing distortion is a major concern for automotive body structures consisting of thin panels, residual stresses gain more attention in thick-section components. In nuclear engineering, welding residual stress (WRS) in dissimilar metal welding (DMW) plays a significant role in the stress corrosion cracking (SCC) processes (Ref. 8). Due to material property mismatch and multiple welding passes, the WRS develops a complex distribution that is difficult to predict or measure, especially when the joint is large in scale. To refine residual stress calculation procedures, the WRS analysis validation program led by the U.S. Nuclear Regulatory Commission (NRC) and Electric Power Research Institute (EPRI) proposed an international round robin to predict residual stresses in a prototypical pressurizer surge nozzle (Ref. 9). A two-dimensional (2D) axisymmetric finite element model (Refs. 10, 11) was used for the finite element analysis (FEA) by all participants. The solution accuracy of the 2D model relies heavily upon the user's knowledge of welding mechanics to rationalize heat input and boundary conditions, and the simulations of subsequent welding repair and local postweld heat treatment (PWHT) are not feasible in this framework. 


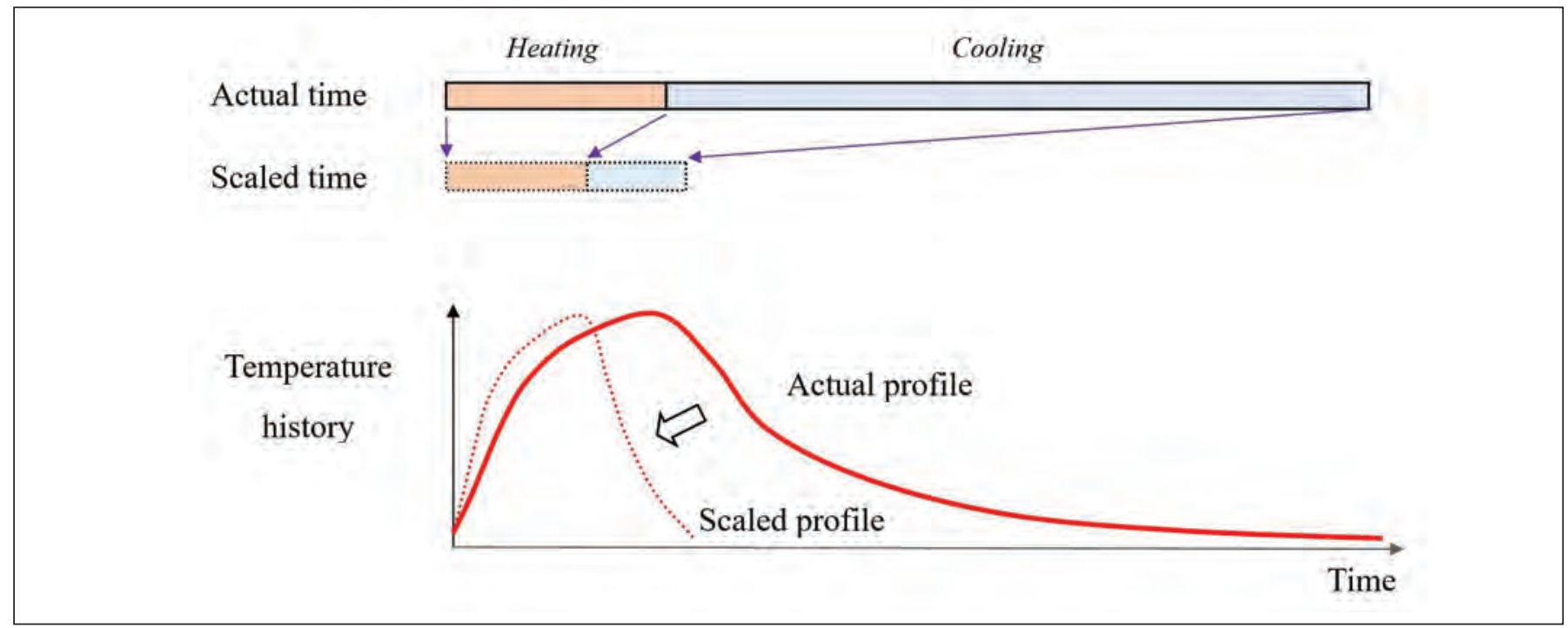

Fig. 1-Schematic drawing of time scaling for a welding simulation.

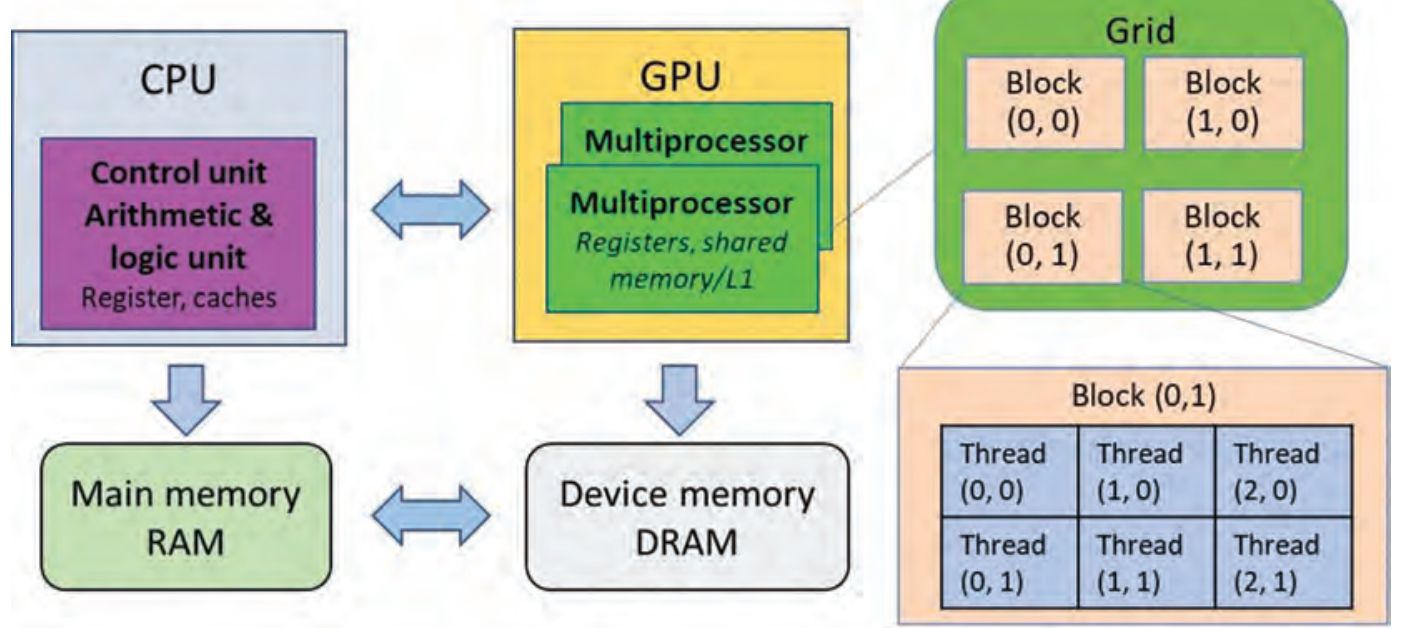

Fig. 2 - Structure of a GPU and correspondence with CPU.

Michaleris et al. (Ref. 12) performed a systematic analysis on the 2D, 3D, and 2D-3D models under small and large deformation assumptions. They concluded that a 2D model resulted in a less accurate prediction of WRS and was not suitable for buckling distortion analysis. Dong et al. (Ref. 13) stated that great care should be taken when assigning boundary conditions in the simplified 2D models. To avoid the uncertainties within the 2D models, a full 3D model needs to be used in pursuit of high-fidelity WRS prediction.

The challenge associated with 3D solid modeling is the significantly higher computational cost compared to the 2D modeling with plane strain or shell elements, posing a major barrier for simulation of industrial-sized welding assemblies. For example, it took days or even weeks (Refs. 14-16) to simulate a meter-long weld model using general commercial software. The computational cost can be reduced by advanced simulation approaches such as adaptive mesh refinement (Ref. 17) and the iterative substructure method (Ref. 18), resulting in an acceleration factor of $3-10$. The scope of numerical simula- tion can be greatly extended if computational performance can be further improved by an acceleration factor of 50-100, particularly considering the needs for welding process optimization. Currently, most welding simulations are based on the implicit finite element method (FEM) that requires the solution of large simultaneous linear equations. A comparative study (Ref. 14) and recent internal studies have shown that parallel computing with commercial code Abaqus beyond 64 cores gains only marginal additional efficiency in welding simulation. This behavior can be explained by Amdahl's law (Ref. 19), which states that speedup is limited by the serial part of the program, such as temperature reading/broadcasting and matrix factorization.

In developing methods to take further advantage of parallel computing potentials in welding simulation, the explicit FEM simulation becomes an attractive candidate to be used on a massive core computer platform because it does not require assembling and solving the global matrix. Ma and Umetsu (Refs. 20, 21) initiated the application of explicit FEM in ana- 


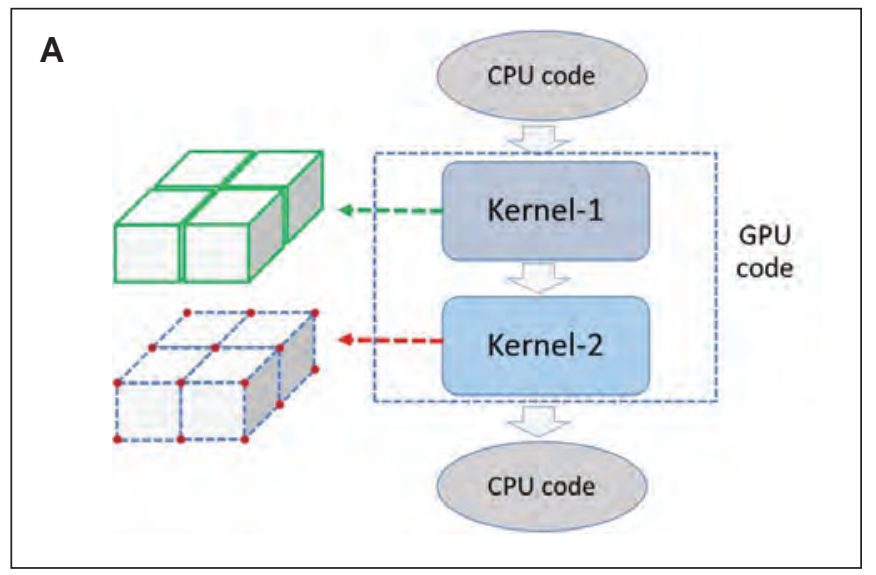

\section{B Kernel-1 (Loop elements)}

Obtain strain increment from displacement field,

Deduct thermal strain from total strain,

Check yield condition and update stress and strain

Calculate force value at each degree of freedom

\section{Kernel-2 (Loop nodes)}

Assemble nodal forces based on node-element connectivity

Calculate new acceleration \& velocity by Eq. (3) (5)

Update temperature, displacement for next time increment

Fig. 3 - Computational flow for a time integration step: A - CPU and GPU code; B - kernels detailing calculation items.
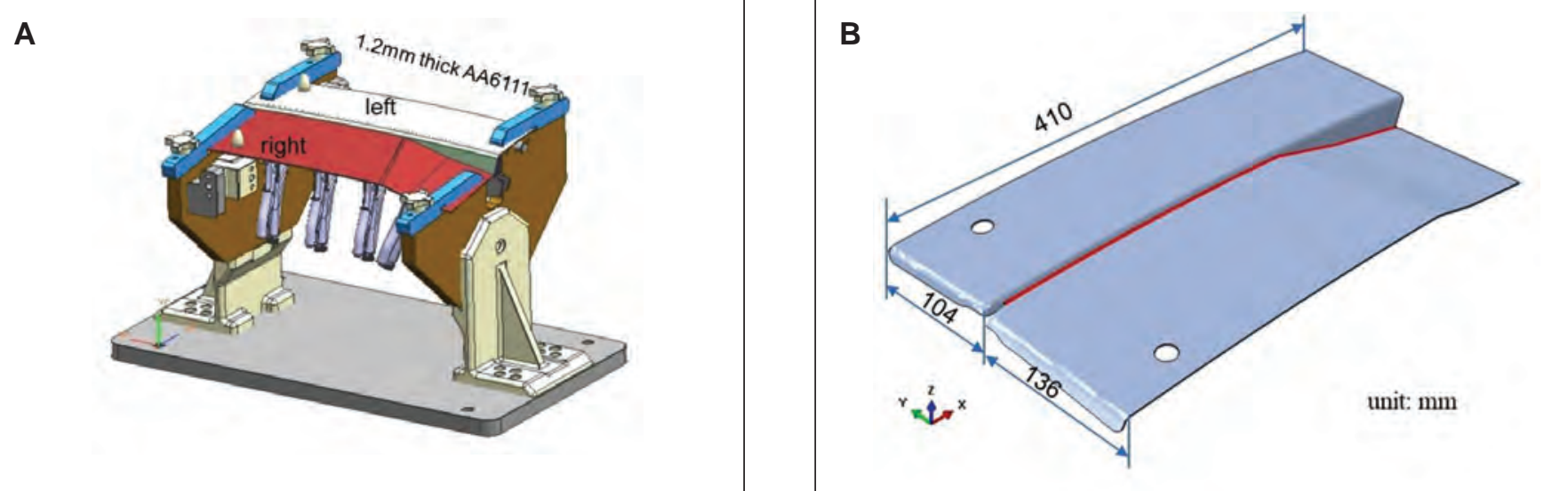

Fig. 4-Laser brazing of automotive panels: A - Experiment setup with clamping on ends; B - panel geometry and major dimensions.

lyzing welding stress and distortion. Using the LS-DYNA software and mass scaling techniques, they were able to accelerate the welding analysis by more than seven times compared with the simulation by implicit FEM. Ikushima and Shibahara (Ref. 22) developed an idealized explicit FEM by selecting the appropriate density for different elements. An acceleration factor of 12 times was achieved compared to the implicit FEM solver. Recently, the authors developed an efficient graphics processing unit (GPU) code at Oak Ridge National Laboratory with a sufficient accuracy and acceleration factor of more than 70 times as demonstrated by benchmark examples (Refs. 23, 24).

This study showcases the capability of GPU-based explicit FEM in predicting transient stress and distortion in realworld welding components. Laser brazing of an automotive coach peel joint was analyzed in full scale using the 3D solid elements. Welding distortion under different clamping conditions was predicted and discussed. In addition, the NRC international round robin was revisited by using efficient 3D FEA. With the improved WRS prediction, welding repair simulation was also enabled for such a large-scale DMW.

\section{Numerical Approach}

\section{Explicit FEM with Time Scaling}

To reduce computational costs, the fusion welding process is generally solved in a one-way coupled manner with heat transfer and mechanical analyses performed in sequence (Refs. 10, 13, 18). Compared with heat transfer analysis, the mechanical analysis requires a significantly longer time because of the greater degrees of freedom (DOF) to solve (Ref. 18). The focus of this study is the acceleration of the mechanical analysis portion of welding stress and distortion. For a simulation approach based on implicit FEM, the solution of loaddisplacement equations (Equation 1) involves arithmetic operations on the order of approximately $N^{2}-N^{3}$ depending on the matrix solver, where $N$ is the number of DOFs, $K$ is the assembled stiffness matrix, $f$ is the load vector, $u$ is the nodal displacement vector, and $i$ denotes an iteration step.

$$
\begin{gathered}
K_{N \times N}^{i} \Delta u_{N \times 1}^{i}=\Delta f_{N \times 1}^{i} \\
u_{N \times 1}^{i+1}=u_{N \times 1}^{i}+\Delta u_{N \times 1}^{i}
\end{gathered}
$$

On the other hand, explicit FEM aims at the nodal acceleration $\left({ }^{\ddot{u}}\right)$ induced by unbalanced internal load $(I)$ and external load $(F)$. Equations 3-5 summarize the time integration scheme (Ref. 25) for the nodal quantities at the DOF ( $k$ ) written in scalar form. Here, ${ }^{u}$ denotes nodal displacement and ${ }^{\dot{u}}$ denotes velocity. With the lumped mass technique, the com- 

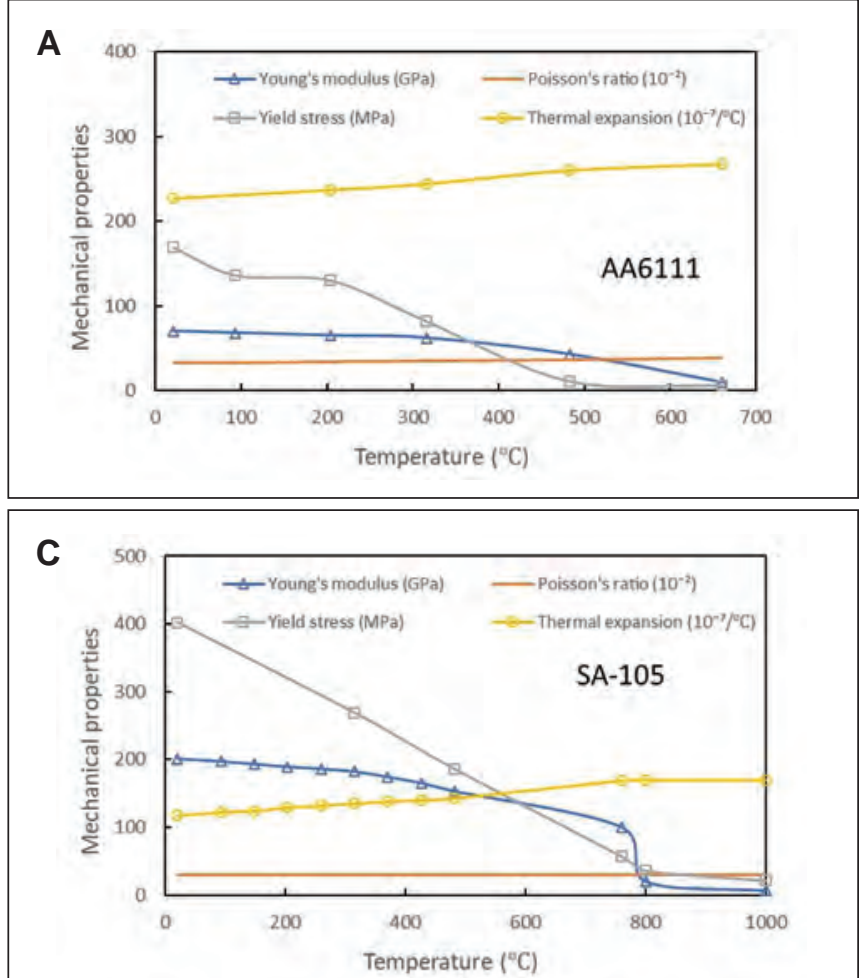

Fig. 5 - Temperature-dependent material properties: A - Aluminum alloy; B - stainless steel; $C$ - carbon steel; D - nickel alloy.

putational cost is roughly linear $O\left(N^{1}\right)$ with the number of DOFs. This is particularly suitable for solving large-scale finite element models via parallel computing on the computer processing unit (CPU) and GPUs (Refs. 26, 27).

$$
\begin{gathered}
\ddot{u}_{k}^{t}=\left(F_{k}^{t}-I_{k}^{t}\right) / M_{k} \\
\dot{u}_{k}^{t+0.5 d t}=\dot{u}_{k}^{t-0.5 d t}+\ddot{u}_{k}^{t} \cdot d t \\
u_{k}^{t+d t}=u_{k}^{t}+\dot{u}_{k}^{t+0.5 d t} \cdot d t \\
d t \approx d L \cdot \sqrt{\rho / E}
\end{gathered}
$$

In the above equations, $k$ is the nodal DOF number $(1-N), t$ is the welding time, and $d t$ is the time increment in the explicit integration, which is usually a very small value. It can be calculated from the Courant-Friedrichs-Lewy condition that a stress wave should not pass through an element (with a characteristic length of $d L$ ) within $d t$, as shown in Equation 6. For aluminum with Young's modulus $E=70$ GPa and density $\rho=2700 \mathrm{~kg} / \mathrm{m}^{3}$, the time increment will be as small as $0.2 \mu \mathrm{s}$ if the minimum element size is $1 \mathrm{~mm}$. In the case of fusion welding, the heating and cooling time ranges from minutes to hours, which can result in a great number of time integration cycles. In general, mass scaling and time scaling techniques can be used to accelerate computation for explicit simulations (Refs. 28, 29). The scaling factor (SF) is usually predefined based on a user's experience
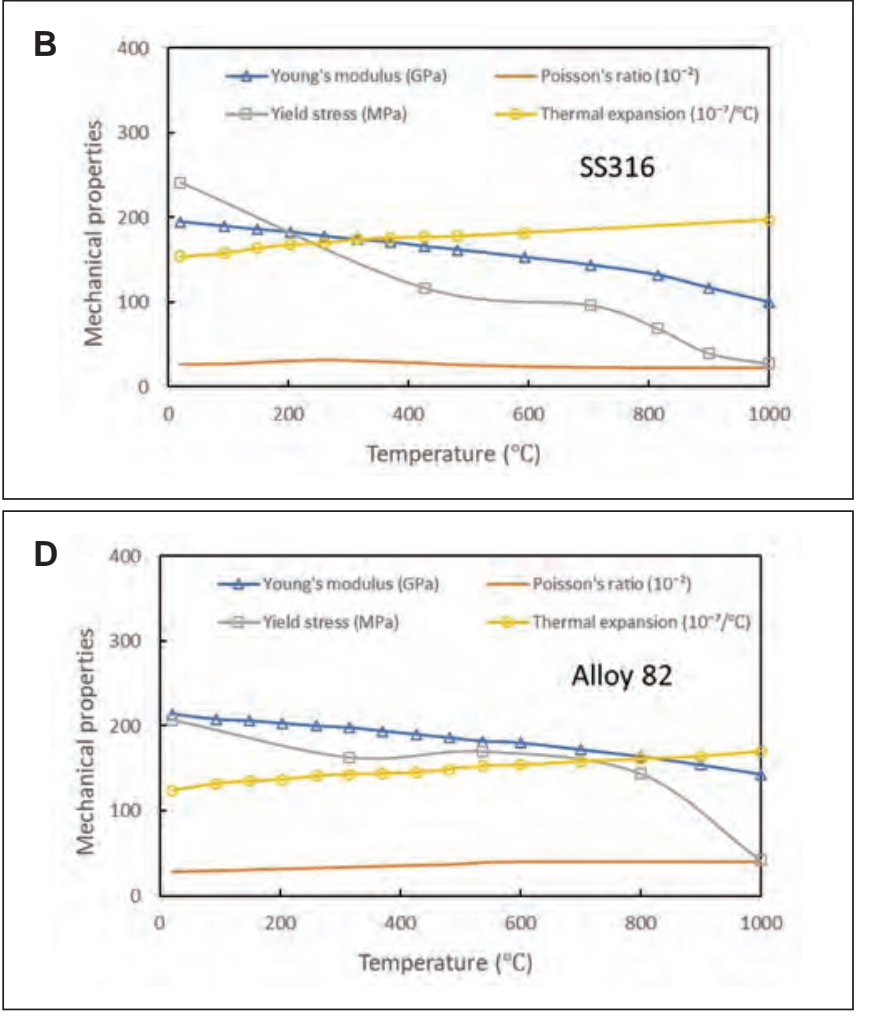

or a sensitivity study. In an earlier study (Ref. 24), the optimum SF was calibrated by the inherent strain concept to significantly reduce the time integrated over the heating process. To account for a longer cooling time span, a variable time SF in the range of 1-100 times SF was employed, as illustrated in Fig. 1. The computational time was greatly reduced because the simulation event became much shorter (less than 1/SF of the original time span) in an explicit simulation.

\section{GPU Implementation to Accelerate Time Integration}

GPU was initially designed for the rapid manipulation of image data, and later it was extended to perform general computing traditionally handled by CPUs. The advent of programming frameworks such as $\mathrm{CUDA}^{\circledR}$, OpenACC ${ }^{\circledR}$, and OpenCL ${ }^{\mathrm{TM}}$ has greatly advanced scientific computing based on GPU/CPUs (Ref. 30), leading to the fast growth of computing power in modern supercomputers. For FEM codes written in Fortran, the PGI Group developed a compiler CUDA Fortran, which offers seamless connection with CUDA libraries (Ref. 31). In recent years, the increasing double-precision capabilities in GPU devices, such as NVIDA ${ }^{\circledR}$ Tesla $^{\circledR}$ and Pascal ${ }^{\mathrm{TM}}$ product series, have attracted significant interest from the FEM community. Essentially, one GPU contains thousands of cores that are highly parallel and thus can process large blocks of data very efficiently. Figure 2 is a schematic of GPU architecture and memory access. Thread blocks can be executed in parallel or in series because they are independent. A kernel is called by CPU and executed on GPU multiprocessors in the form of grids. A 


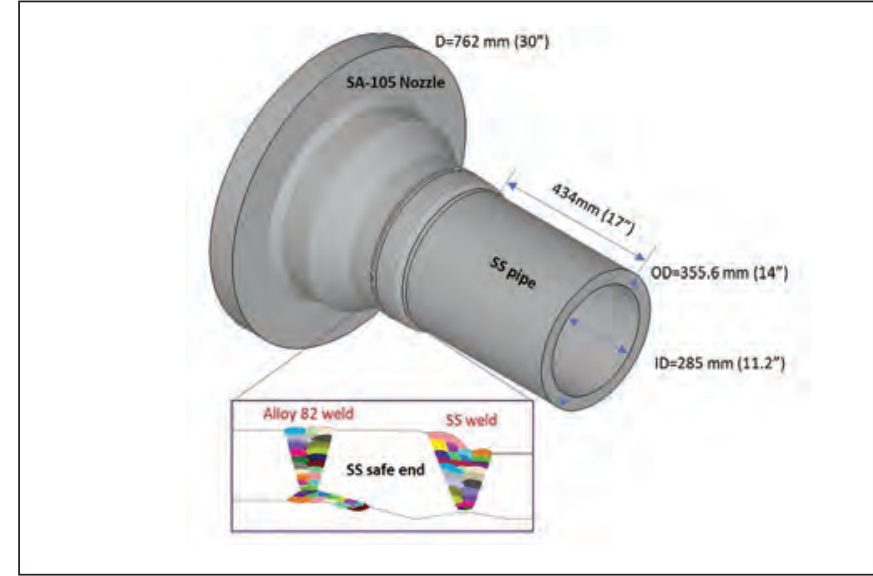

Fig. 6 - NRC/EPRI Phase IIb round robin mockup geometry and weld passes.

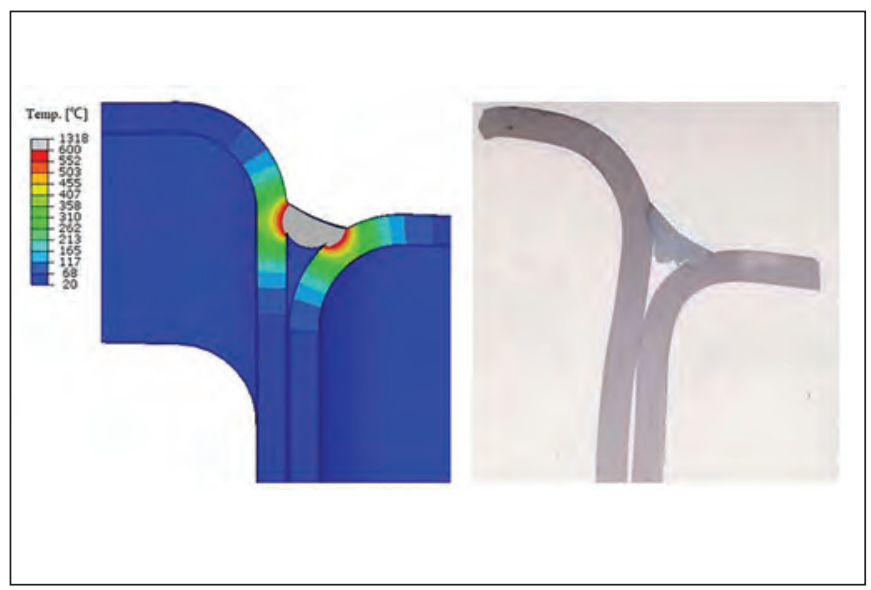

Fig. 7 - Comparison of the fusion zone between the numerical model and the experiment.
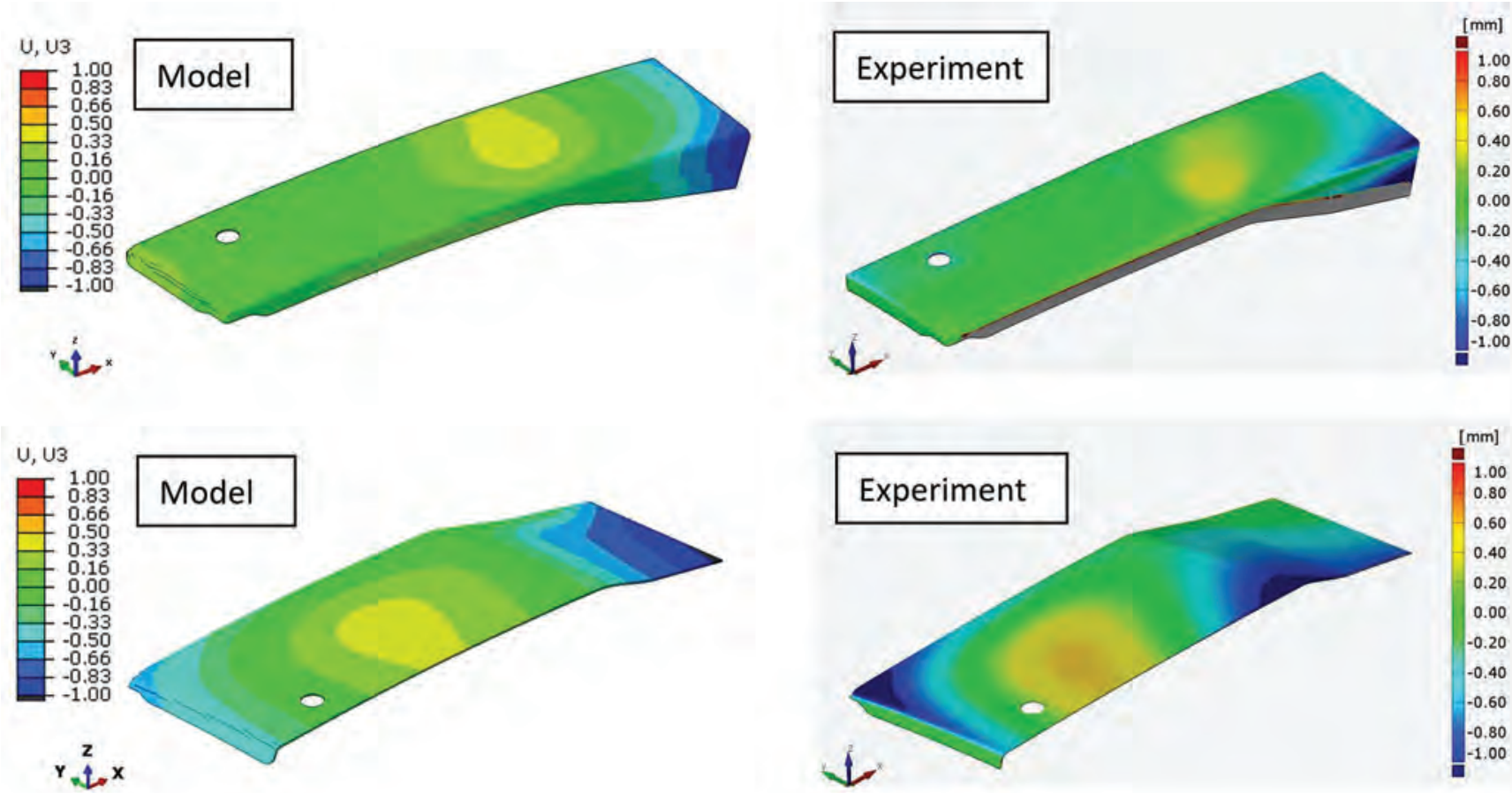

Fig. 8-Out-of-plane distortion of laser brazed panels (Case la), with the left panel on the top and the right panel at the bottom.

grid is composed of many thread blocks. Threads within a block can cooperate by sharing data through shared memory and by synchronizing their execution to coordinate memory accesses. More information about GPU structure and compiling can be found in Ref. 30 .

For the explicit FEM code developed in-house, Fig. 3 illustrates the computational flow of a time incrementation during FEA. Two computing kernels were designed for calculation on elements and nodes, respectively. Most of the computational time (> 80\%) was spent in Kernel-1 because the stress and strain tensors were computed for each element. The contribution of nodal unbalanced force from each element was also integrated in this loop. In addition, a correction force to alleviate the hourglass effect needed to be computed. In Kernel-2, time integration procedures were conducted for each DOF at a node. The information between the two kernels were communicated through the nodeelement array, which was stored in shared memory. The performance of the GPU was largely dependent on the register size of the device because many local variables were defined by kernels. To reduce the use of variables, a call of subroutine in kernels should be avoided, and local arrays should be used repeatedly as much as possible. The current version of the explicit FEM code was based on the Linux ${ }^{\mathrm{TM}}$ operating system and workstation type NVIDIA GPU, but it could be recompiled into a Windows version to run on a personal computer equipped with a regular graphics card such as the GeForce GTX series. 


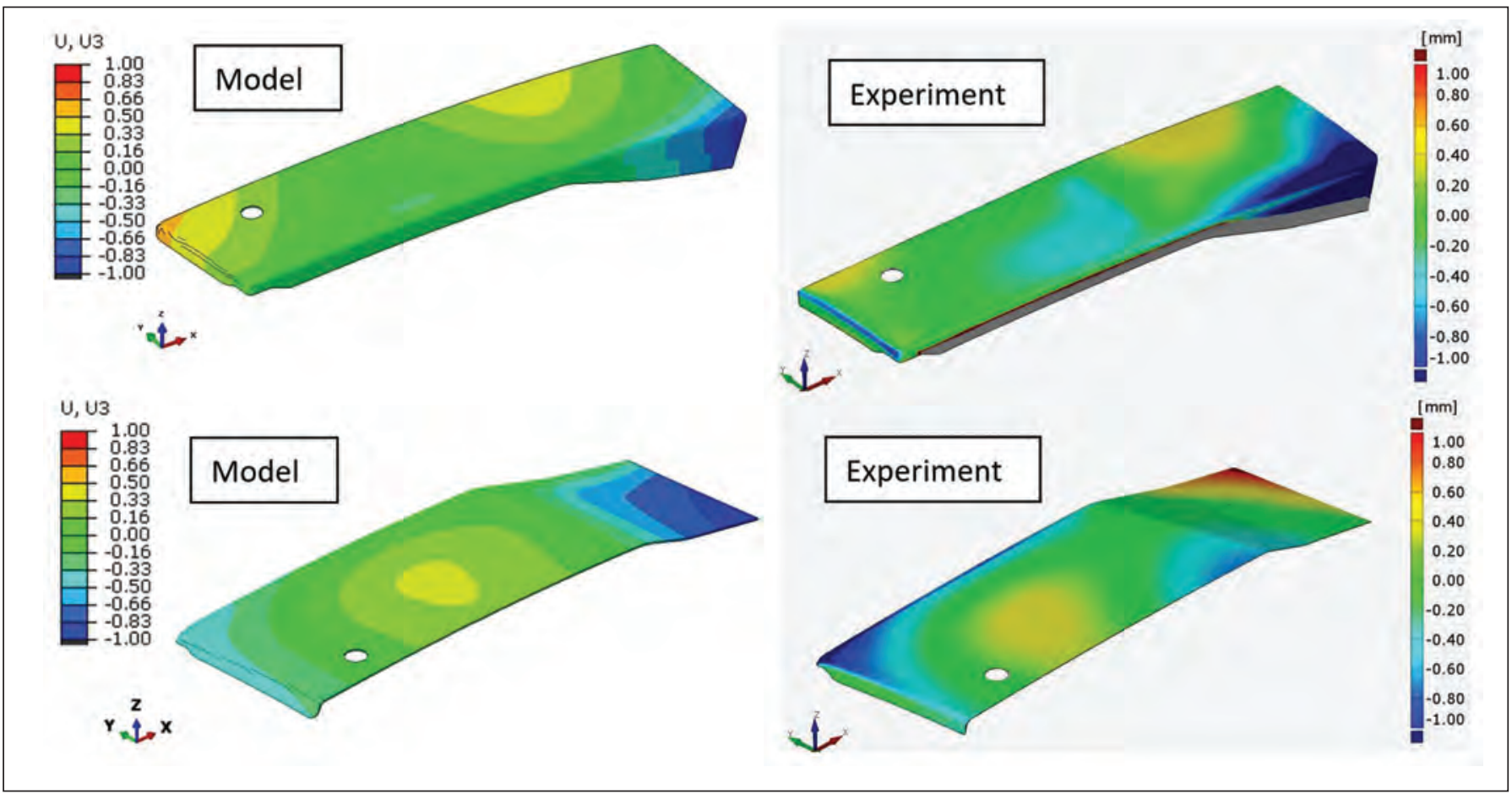

Fig. 9-Out-of-plane distortion of laser brazed panels (Case 1b), with the left panel on the top and the right panel at the bottom.

\section{Experiments and Modeling}

\section{Laser Brazing of Automotive Aluminum Panels}

Coach peel joints are typical in exterior components of automotive bodies, such as the decklid and roof structure (Ref. 2). Figure 4 illustrates the experimental setup and specimen geometry. The left and right AA6111 panels were clamped and then laser brazed. Four vises were also employed to fix the bottom portion of the aluminum panels. The two panels had the same thickness of $1.2 \mathrm{~mm}$ and a length of $410 \mathrm{~mm}$. The right panel had a large curvature near the bottom end, and laser irradiation was preset to be perpendicular to the braze line to ensure a consistent heat input during the joining process. The laser power was $4 \mathrm{~kW}$ with a 0.96-mm laser spot size, and travel speed was 55 $\mathrm{mm} / \mathrm{s}$. The braze wire was American Welding Society (AWS) A5.8, Specification for Filler Metals for Brazing and Braze Welding, BAlSi-4 (AA4047), and the wire feeding speed was 70 $\mathrm{mm} / \mathrm{s}$. The laser brazed panels were air cooled prior to distortion measurement using an optical 3D coordinate measuring device (ATOS scanner).

In this study, the authors used solid elements to represent the detailed braze bead shape. First, a computer-aided design surface model was meshed into 2D shell elements. Then, the solid mesh was generated by extruding shell elements along the thickness direction. The finite element model consisted of 621,238 nodes and 510,394 eight-node hexahedral elements. The thermal physical material properties for the $\mathrm{Al}$ alloy can be found in a previous article (Ref. 32). To model heat transfer due to localized fluid flow in the molten pool, an artificially increased heat conductivity, which is several times greater than the room temperature value, was applied for temperatures greater than the filler metal melting point (Ref. 10). A Goldak heat source model (Ref. 33) was employed to reproduce the thermal history after calibrating the brazing bead shape. The semiaxes of the front and rear ellipsoid in the Goldak model were both set to be $1.0 \mathrm{~mm}$ in the brazing and width directions, respectively, as well as $1.5 \mathrm{~mm}$ in the laser irradiation direction. The stress analysis was carried out using explicit FEM for the brazing process under clamping and implicit FEM for the clamping-removal stage, considering its fast convergence. The temperature-dependent mechanical properties of $\mathrm{Al}$ alloy used in the experiment are shown in Fig. 5A. Element activation was implemented within the brazing process and temperature-dependent material properties were used. After both the laser brazing and cooling process were analyzed by the explicit FEM, the displacement and residual stress data was transferred to implicit FEM to analyze the final distortion due to clamping removal.

\section{GTAW of a Dissimilar Weld in a Nuclear Power Plant}

In the NRC international round robin (Ref. 9), a mockup representing a typical joint in a pressurized water reactor coolant system was fabricated to study residual stresses. A carbon steel nozzle and a stainless steel (SS) safe end were joined by a nickel-based DMW. Figure 6 is a drawing of the mockup geometry, which consists of three basic components: the carbon steel nozzle, a 308 SS safe end, and a 316 SS pipe. The SA-105 nozzle was first buttered with AWS A5.15, Specification Welding Electrodes and Rods for Cast Iron, ERNiCr-3 (Alloy 82), then heat treated and machined. Then, Alloy 82 was deposited on the outer and inner diameter 
A

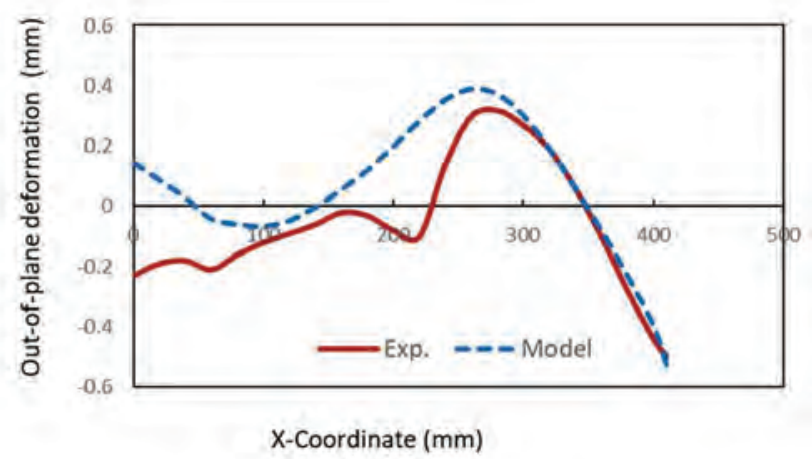

C

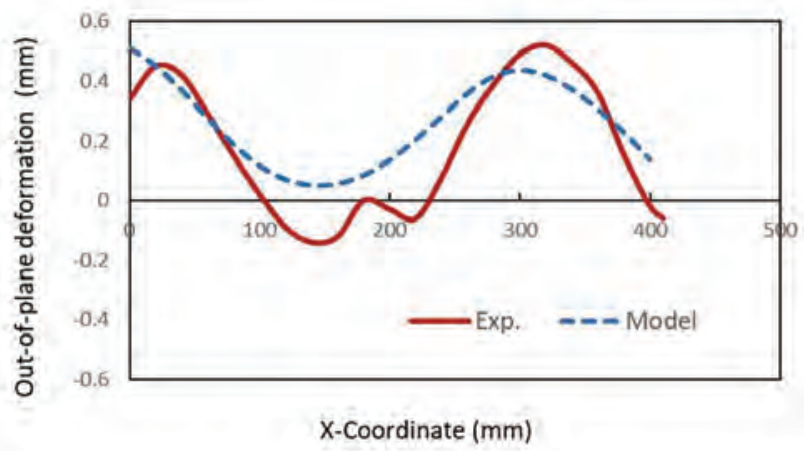

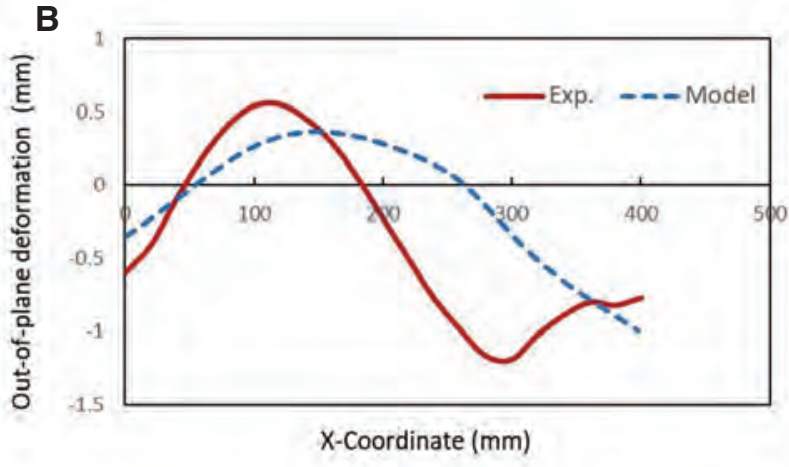

D

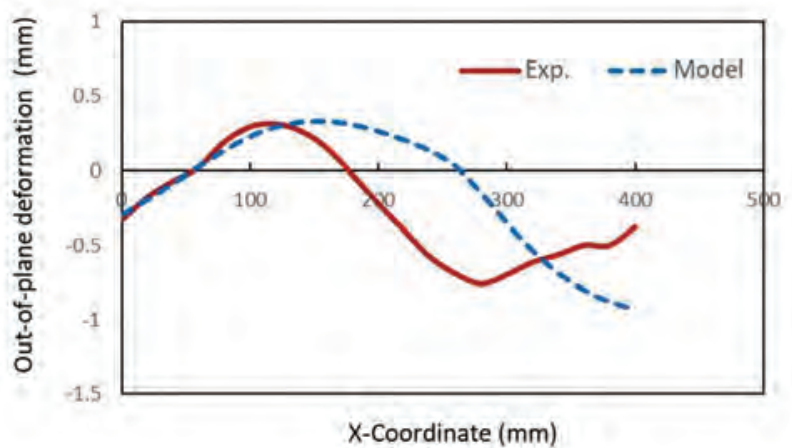

Fig. 10 - Comparison of out-of-plane deformation on the edge: A - Left panel in Case la; B - right panel in Case la; C - left panel in Case $\mathrm{lb} ; \mathrm{D}$ - right panel in Case $\mathrm{lb}$.

sides by gas tungsten arc welding (GTAW). The Alloy 82 weld was the main DMW in the mockup. Finally, the 308 SS safe end was welded to 316 SS pipe. Due to the limitation of state-of-the-art modeling techniques, a 2D axisymmetric model was employed for the numerical study by all participants. In this study, the DMW was simulated via 3D solid modeling using a GPU-accelerated explicit FEM code. The material properties of each material used in fabrication of the mockup are shown in Fig. 5B-D.

Due to the large diameter of the nozzle and 64 total passes, the number of elements and nodes for manufacturing process simulation were $1,273,440$ and $1,340,640$, respectively. The size of elements near the weld zone (WZ) was about $2 \mathrm{~mm}$. Each node had three translation freedoms (X, $\mathrm{Y}$, and $\mathrm{Z}$ directions). Elements of the welding passes were initially deactivated and then gradually activated according to the transient temperature at each welding pass. The initial and room temperatures were defined as $20^{\circ} \mathrm{C}$. For this large model, a 3D FEA using commercial software was not feasible because the analysis of only the DMW part can take several years (Ref. 23). Therefore, the transient thermo-me- chanical analysis was analyzed by applying an in-house code, and the results were compared with those of 2D modeling as well as the experimentally measured data (Ref. 34).

\section{Results and Discussion}

\section{Brazing Distortion Under Different Clamping Conditions}

As shown in Fig. 7, the bead that resulted from brazing had a fillet shape with about a 1.0-mm-wide connection to the two panel plates. By using a Goldak heat source model during heat flow analysis, a reasonable bead shape was predicted as indicated by the region with a peak temperature greater than $600^{\circ} \mathrm{C}$. The width of the joint interface was about $1 \mathrm{~mm}$ on both sides, indicating a reasonable connection between the left and right panels. Two cases brazed under different clamping conditions were investigated by the GPU-based explicit FEM simulation approach. Case 1a represents the clamping condition with the left and right sides

\begin{tabular}{lccc}
\hline \multicolumn{3}{l}{ Table 1-Computational Cost in Mechanical Analysis of the Large Weld Structures } \\
\multicolumn{1}{c}{ Software } & Abaqus Standard (Estimated from Initial Steps) & \\
\hline Configuration & $8 \mathrm{CPU}$ threads & $8 \mathrm{CPU}+1 \mathrm{GPU}$ & $1 \mathrm{CPU}+1 \mathrm{GPU}$ \\
Auto-panel brazing & $252 \mathrm{~h}$ & $2 \mathrm{~h}$ & $\mathrm{GPU}-\mathrm{hxplicit}$ FEM \\
Large pipe welding & 19.6 years & 8.5 years & 3.2 days \\
\hline
\end{tabular}



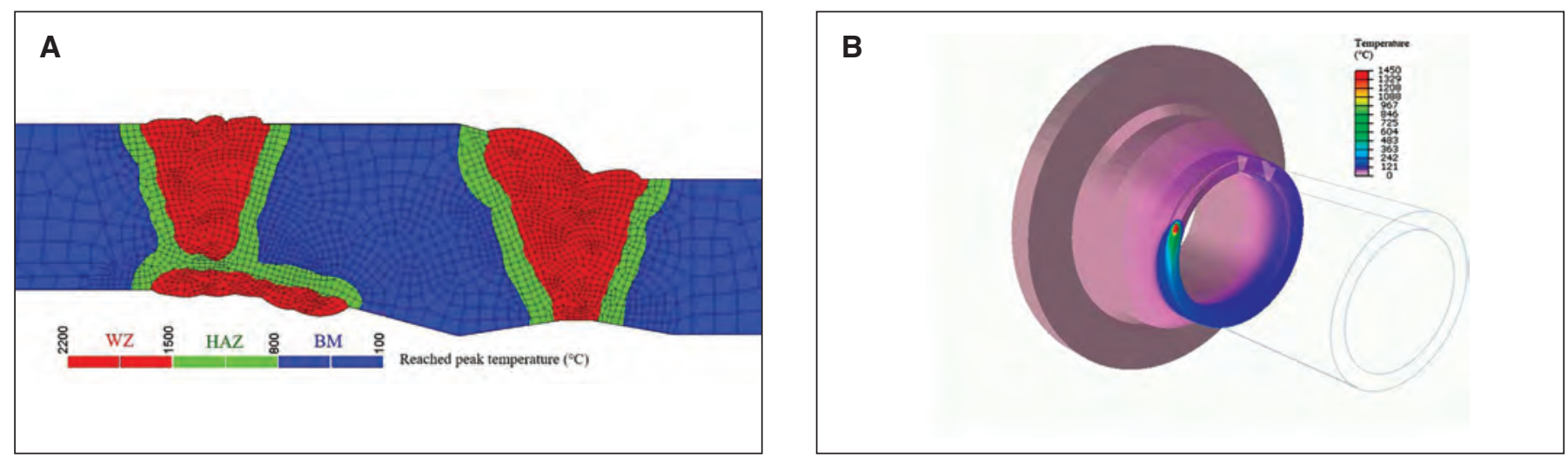

Fig. 11 - Thermal analysis results: A - WZ and HAZ prediction; B - transient temperature at the tenth welding pass (the SS pipe is hidden to provide a view of the weld pool).
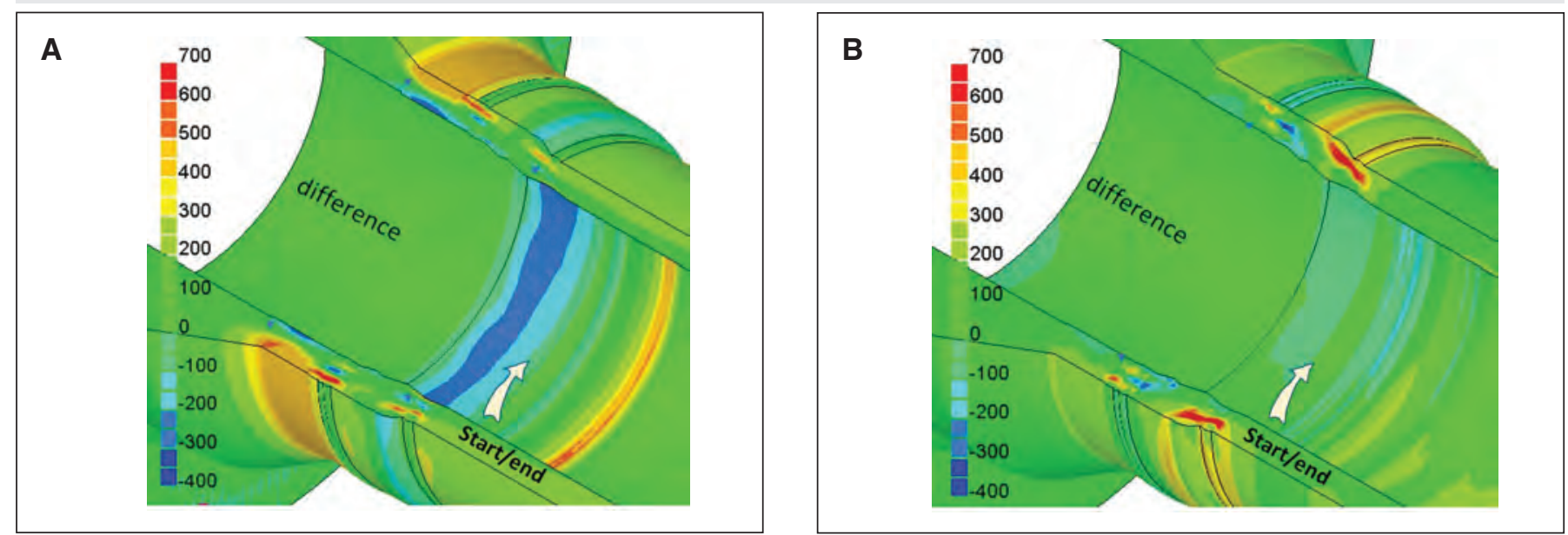

Fig. 12 - WRS of the DMW joint: A - Axial stress; $B$ - hoop stress (unit: MPa).

clamped, and Case $1 \mathrm{~b}$ represents the condition with only the left side clamped. The external clamping fixtures were modeled using fixed nodal displacement in the contact direction. The laser-brazing-induced distortion after clamping removal was predicted using the same boundary condition as that in measurement to eliminate rigid body motion.

The comparison of experimentally measured and simulated distortion is presented in Figs. 8 and 9 for the two subcases ( $1 \mathrm{a}$ and $1 \mathrm{~b}$ ) studied. The distortion is relatively small for the panel structure, so the color range is bounded by $\pm 1 \mathrm{~mm}$. Both the predicted and measured distortion contours exhibited that the largest distortion existed near the end part of each panel. In Case 1a, the distortion on the left panel had a bulging mode near the location where the braze line started to deflect downward. A larger area of the right panel exhibited a similar distortion mode in the middle of the flat part. The difference in distortion of the two panels can be attributed to the large curvature and vertical offset of the right panel. In Case 1b, the left panel exhibited a two-wave distortion mode near the edge, which is related to the reduced constraint on the assembly. The right panel still had bulging distortion in the center, which was reflected in both the mod$\mathrm{el}$ and the experiment. The region near the end of the brazing line appeared to bend upward, which is probably underestimated in the simulation due to simplified contact modeling.

For a more qualitative comparison, the out-of-plane distortion along the edge of each panel was extracted from the model and measurement, as shown in Fig. 10. The distortion mode is clearly different in the left and right panels for both Case 1a (left and right panels are clamped) and Case $1 \mathrm{~b}$ (only the left panel is clamped). In Case $1 \mathrm{~b}$, the distortion in the left panel has a lower magnitude compared to that in Case 1a. The simulation results reasonably agreed with the experimental results in terms of deformation trend and magnitude. The prediction accuracy may be improved if the initial deformation and stress of the panel can be considered in the numerical model. For the sheets with a curved flange, the initial stress due to forming can be large, which will contribute to the out-of-plane distortion. For the abovementioned stress analysis, the computation for each case was finished within $2 \mathrm{~h}$ using a GPU and an accelerated explicit FEA. As shown in Table 1, the computational time using Abaqus implicit FEM took one to two weeks, as estimated from the trial analysis of the initial half-second brazing. The convergence to reach a final solution was challenging because the molten pool had little support at the bottom, and the material exhibited softening at high temperatures and strains. By using the explicit FEM, such highly nonlinear problems can be solved more easily and smoothly. With a validated model, changes to the brazing process, such as reduced heat input and optimized panel geometry, can be investigated to minimize the brazing dis- 

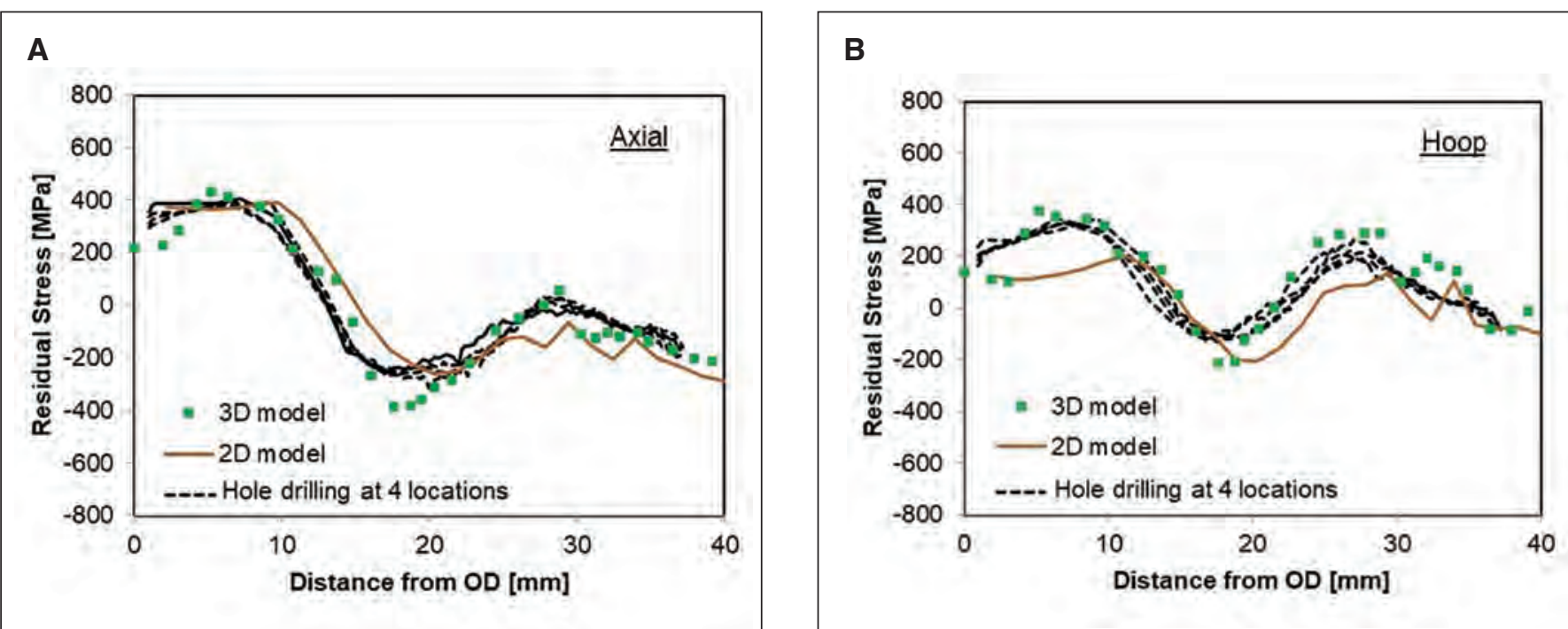

Fig. 13 - Comparison of residual stresses by $2 D$ and $3 D$ numerical models: $A-$ Axial stress; $B$ - hoop stress.

tortion in real production. It is noted that the heat conduction analysis by implicit FEM took $7.6 \mathrm{~h}$, which is longer than the mechanical analysis ( $2 \mathrm{~h}$ ) by GPU-accelerated explicit FEM. The coupled thermomechanical explicit FEM will be investigated to reduce the computational time with the appropriate acceleration scheme for heat conduction analysis. In such a computation framework, the effort in model setup and data transfer will be minimized, enabling a more efficient industrial application of the current code.

\section{Residual Stresses of the DMW Joint}

For the NRC mockup model, the predicted peak temperature and transient temperature during welding are presented in Fig. 11. Reasonable representation of the WD WZ and heat-affected zone (HAZ) as indicated by the peak temperature achieved can be confirmed. The buttering process was not included in the current model because the residual stress due to buttering was mostly relieved by the machining and PWHT process. For high-fidelity prediction in the mechanical analysis, a dynamic hardening rule was applied for material behavior at elevated temperatures with experimentally quantified material parameters (Ref. 34).

Figure 12 is a graphical representation of the global WRS in the mockup DMW joint. For visualization purposes, a quarter part of the welded component was removed in postprocessing. The overall stress contour at the two sections were similar to one another, but the high-stress region at the weld start location (0-deg section) was greater than that at the 90-deg section. During welding, material was gradually deposited in the weld groove, and the restraint built to the largest value at the end of the welding process. A 2D axisymmetric model simulated a welding scenario with simultaneous heating and cooling of each welding pass, which did not reflect the actual heat input and constraint condition. Thus, welding start/end effects cannot be captured in the 2D framework. In addition, repair welding, actual clamping, and backstep welding all require a 3D model for realistic simulation. The 3D stress and strain distribution will be

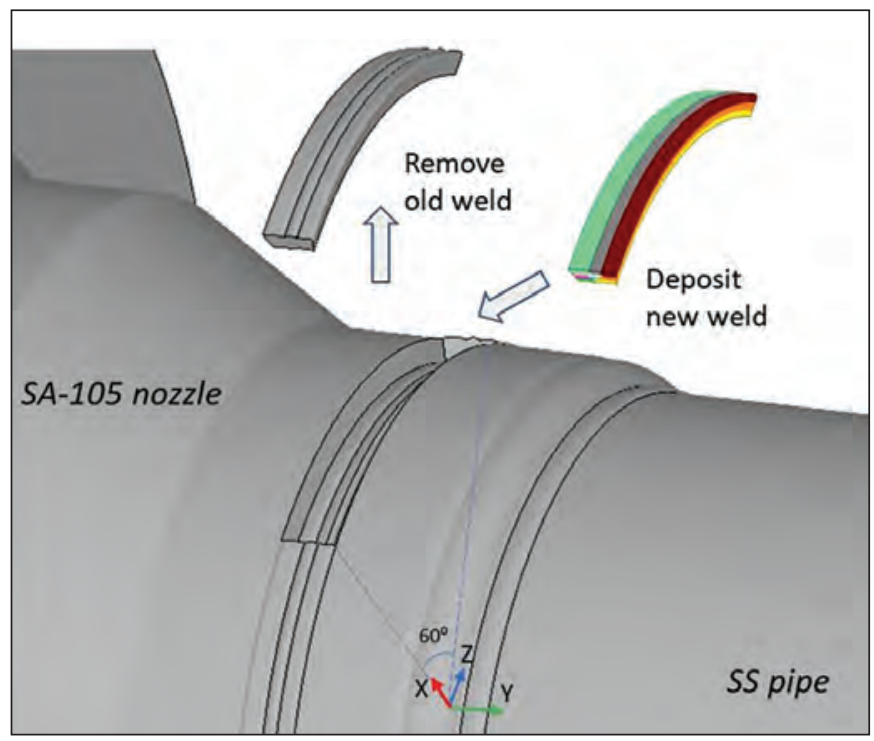

Fig. 14 - Schematic of the weld repair location and geometry.

more critical in partial welding repair and local heat treatment, for which a 2D simplified model is inappropriate to simulate these processes.

The experimentally measured data by deep hole drilling was employed to validate the simulation results. The original 2D model data was also plotted as a reference. Figure 13 are graphs of the distribution of the hoop and axial residual stress in the DMW through-wall thickness. Using the experimentally measured data as a baseline, the 3D model better predicted the stress distribution than the 2D model in overall trend and magnitude as a result of a fullscale process simulation. The axial stress and hoop stress near the outer surface were both in a tensile state with a magnitude of approximately $400 \mathrm{MPa}$. Such an effective prediction provides insight into regions that are susceptible to SCC as well as related welding and corresponding PWHT techniques to manage the stress level. For this large 3D model, the computational cost of the in-house GPU 

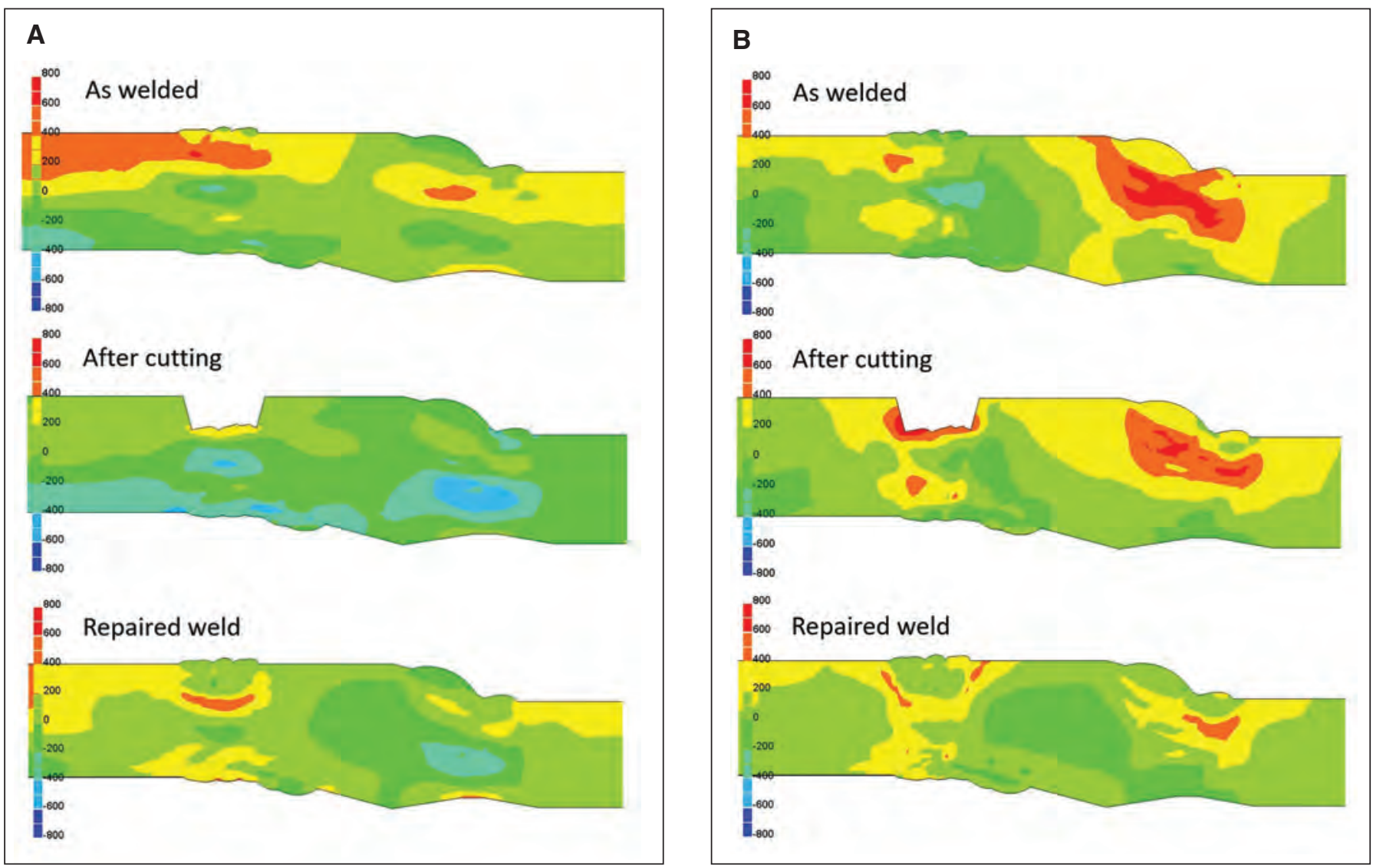

Fig. 15 - Evolution of residual stresses in DMW: A - Axial stress; B - hoop stress (unit: MPa).

code was three days, which is tolerable for engineering designs. It should be noted that a newer-version GPU or parallel run in multiple GPUs will enable faster computation of the WRS problem.

\section{Residual Stresses after Welding Repair}

The pressure nozzle undergoes high-temperature thermal cycles and internal pressure loading in daily operations. SCC and creep damage will accumulate in the WZ and HAZ. Welding repair will be required if significant cracks or damage are detected in the weld joint during routine inspection. Depending on the size of the damage zone, full or partial welding repair (Refs. 35, 36) can be performed. The repair excavation length and depth can be determined after nondestructive testing and evaluation. A minimum extent of replacement is usually desired for large-diameter nozzles in power plants for economic reasons. An earlier survey (Ref. 37) revealed that $40 \%$ of participant utilities reported subsequent cracking occurring after welding repair, particularly in dissimilar material welds and nickelbased welds. This can be related to high residual stresses in the weld repair because $70 \%$ of the repairs were conducted without implementing PWHT. The pre/postheating, heat input, and welding pass layout can be optimized to reduce the residual stress caused by welding repair (Refs. 38-40) and thereby extend the service life of ageing power plants. In this study, the partial welding repair with a 60-deg arc length was assumed, and the excavation depth was approximately $10 \mathrm{~mm}$ from the outer diameter (Fig. 14). The weld layers followed the same heat input condition of 15-24 passes in the original welding procedure. No initial damage or material degradation was considered in this demonstration example.

To analyze the stress change inside the weld, the residual stresses on the 0-deg section after original welding, mechanical cutting, and subsequent welding repair are presented in Fig. 15. Axial stress in the whole joint was relieved substantially due to the cut, which can be understood from the cut location and original stress distribution. After weld fabrication, the pressurized nozzle in the proximity of the repair location exhibited a high axial stress, which covers a layer of thickness close to weld repair. The removal of material in DMW would directly break the continuity of residual stress in the axial direction. On the other hand, hoop stress in the DMW region exhibited an increased tensile-stress area and magnitude. This was related to the reduced cross section at the DMW as well as the stress rebalance between the DMW and SS weld. The peak hoop stress was approximately 570 $\mathrm{MPa}$ in the dissimilar weld region. With a new weld deposited in the groove, the axial stress increased to $400 \mathrm{MPa}$ at the bottom of the repaired DMW, but the stress near the surface was approximately $200 \mathrm{MPa}$. For the hoop stress component, the region with the high level of stress became smaller compared to the original residual stresses, especially in the SS weld. Part of the stress reduction was attributed to the heat-treatment effect from the weld repair. High tensile stresses seemed to generate at the HAZ of the DMW, which would accelerate creep formation and SCC. Local heat treatment may be applied to the WZ and HAZ to alleviate the 
stress concentration. Such efficient numerical modeling can effectively assist the development of new codes and standards for welding repair of pipe systems in nuclear power plants and oil/gas industries.

\section{Conclusion}

A computationally efficient explicit FEM based on the time scaling scheme and GPU acceleration was applied to model industrial-scale welding components. Two representative welding scenarios - laser brazing of automotive roof panel and multipass arc welding of nuclear powerplant pipe - were simulated by the 3D transient thermomechanical finite element model to predict the brazing/welding distortion and residual stresses. The large-scale simulation revealed important features that are simply not achievable by 2D models. Based on the data and method presented in the paper, the following conclusions are drawn:

1. Laser brazing of an automotive coach peel joint under clamping conditions was simulated in a sequential explicit/implicit FEA framework. The 3D transient thermomechanical analysis was successfully performed for a model with 2 million DOFs in a mere $2 \mathrm{~h}$ on a GPU. In contrast, more than one week will be needed if the model is simulated by commercial software. It revealed that the laser brazing process induced out-of-plane distortion in the panels with a magnitude close to panel thickness $(1.2 \mathrm{~mm})$. Both the left and right panels exhibited bulging distortion but at different locations due to the asymmetry of the brazing joint.

2. The panel distortion mode was influenced by the clamping condition. The left panel had more distortion occurring on the free edge when only the left panel was clamped than in the case of both panels being clamped. In addition, the right panel exhibited twisted distortion near the end of the brazing joint.

3. Multipass arc welding of a large-diameter pipe in the $\mathrm{NRC}$ international round robin was revisited by the $3 \mathrm{D}$ analysis approach. The complex residual stresses distribution in the dissimilar material weld joint between carbon steel and stainless steel were predicted in about three days by novel accelerated explicit FEM. For the weld girth, the axial and hoop stress at the weld start location were different from those at other locations. The WRS by 3D model exhibited a better agreement with experimental measurement than a 2D axisymmetric model.

4. The GPU-accelerated computation approach enabled repair welding simulation on a large pipe with multipass welding. The stress evolution predicted by the model provided insight into high-tensile stress locations and mitigation methods for welding repair.

In conclusion, the computation time was drastically reduced from multiple weeks/years to hours/days when GPU accelerator and time-scaling techniques were applied. The simulation approach can be used for computation-intensive optimization of manufacturing processes to improve product quality and advance welding technology.

\section{Acknowledgment}

This research was sponsored by the U.S. Department of
Energy, Office of Vehicle Technology, under a prime contract with Oak Ridge National Laboratory (ORNL), Oak Ridge, Tenn. ORNL is managed by UT-Battelle LLC. for the U.S. Department of Energy under Contract DE-AC05-00OR22725. The authors would like to express their gratitude to Kyle Douglas and Jason (Yiyu) Wang for their assistance with the technical review of this article.

\section{References}

1. Mittelstädt, C., Seefeld, T., Reitemeyer, D., and Vollertsen, F. 2014. Two-beam laser brazing of thin sheet steel for automotive industry using Cu-base filler material. Phys. Procedia 56: 699-708. DOI: 10.1016/j.phpro.2014.08.077

2. Yang, G., Mohammadpour, M., Yazdian, N., Ma, J., Carlson, B., Wang H. P., and Kovacevic, R. 2017. Cross-beam laser joining of AA 6111 to galvanized steel in a coach peel configuration. Lasers Manuf. Mater. Process. 4(2): 45-59. DOI: 10.1007/s40516-0170036-0

3. Li, C. L., Ding, F. A. N., Yu, X. Q., and Huang, J. K. 2019. Residual stress and welding distortion of $\mathrm{Al} /$ steel butt joint by arcassisted laser welding-brazing. Transactions of Nonferrous Metals Society of China 29(4): 692-700. DOI: 10.1016/S1003-6326(19) 64979-4

4. Tsai, C. L., Park, S. C., and Cheng, W. T. 1999. Welding distortion of a thin-plate panel structure. Welding Journal 78(5): 156-s to 165-s.

5. Yang, Y. P., and Dong, P. 2012. Buckling distortions and mitigation techniques for thin-section structures. Journal of Materials Engineering and Performance 21(2): 153-160. DOI: 10.1007/ s11665-011-9928-x

6. Lou, M., Cai, W., Huang, J., Wang H.-P., Li, Y., Carlson, B. E., and Poss, M. G. 2020. Simulation of laser brazing of sheet panels and parametric studies of thermally-induced distortion reduction. Journal of Manufacturing Processes 60(2): 1-10. DOI: 10.1016/j. jmapro.2020.10.030

7. Shen, J., and Chen, Z. 2014. Welding simulation of filletwelded joint using shell elements with section integration. Journal of Materials Processing Technology 214(11): 2529-2536. DOI: 10.1016/j.jmatprotec.2014.04.034

8. Andresen, P. L., Ford, F. P., Gott, K., Jones, R. L., Scott, P. M., Shoji, T., Staehle, R. W., and Tapping, R. L. 2007. Expert Panel Report on Proactive Materials Degradation Assessment. U.S. Nuclear Regulatory Commission: UREG/CR6923.

9. Rathbun, H. J., Fredette, L. F., Scott, P. M., Csontos, A. A., and Rudland, D. L. 2011. NRC welding residual stress validation program international round robin program and findings. ASME 2011 Pressure Vessels and Piping Conference: 1539-1545. DOI: 10.1115/PVP2011-57642

10. Deng, D., and Murakawa, H. 2006. Numerical simulation of temperature field and residual stress in multi-pass welds in stainless steel pipe and comparison with experimental measurements. Computational Materials Science 37(3): 269-277. DOI: 10.1016/j. commatsci.2005.07.007

11. Barsoum, Z., and Lundbäck, A. 2009. Simplified FE welding simulation of fillet welds - 3D effects on the formation residual stresses. Engineering Failure Analysis 16(7): 2281-2289. DOI: 10.1016/j.engfailanal.2009.03.018

12. Michaleris, P., Zhang, L., Bhide, S. R., and Marugabandhu, P. 2006. Evaluation of 2D, 3D and applied plastic strain methods for predicting buckling welding distortion and residual stress. Science and Technology of Welding and Joining 11(6): 707-716. DOI: 10.1179/174329306X147724

13. Dong, P., Hong, J. K., and Bouchard, P. J. 2005. Analysis of residual stresses at weld repairs. International Journal of Pressure Ves- 
sels and Piping 82(4): 258-269. DOI: 10.1016/j.ijpvp.2004.08.004

14. Feng, Z., Chen, G., and Chen, J., 2015. High-Performance Computing for Weld Residual Stress Modeling: A Feasibility Evaluation. Program on Technology Innovation. Palo Alto, Calif.: Electric Power Research Insitute; 3002006526

15. Huang, H., Tsutsumi, S., Wang, J., Li, L., and Murakawa, H. 2017. High performance computation of residual stress and distortion in laser welded 301L stainless sheet. Finite Elem. Anal. Des. 135: 1-10. DOI: 10.1016/j.finel.2017.07.004

16. Huang, H., and Murakawa, H. 2015. Dynamic mesh refining and iterative substructure method for fillet welding thermo-mechanical analysis. Comput. Model. Eng. Sci. 106(3): 187-201. DOI: 10.3970/cmes.2015.106.187

17. Lindgren, L. E., Häggblad, H. Å., McDill, J. M. J., and Oddy, A. S. 1997. Automatic remeshing for three-dimensional finite element simulation of welding. Comput. Methods Appl. Mech. Eng. 147(3-4): 401-409. DOI: 10.1016/0045-7825(97)00025-X

18. Murakawa, H., Ma, N., and Huang, H. 2015. Iterative substructure method employing concept of inherent strain for largescale welding problems. Welding in the World 59(1): 53-63. DOI: 10.1007/s40194-014-0178-z

19. Hill, M. D., and Marty, M. R. 2008. Amdah's law in the multicore era. Computer 41(7): 33-38. DOI: 10.1109/MC.2008.209

20. Ma, N., and Umezu, Y. 2009. Application of explicit FEM to welding deformation: Analysis. Welding International 23(1): 1-8. DOI: $10.1080 / 09507110802348884$

21. Ma, N. 2016. An accelerated explicit method with GPU parallel computing for thermal stress and welding deformation of large structure models. The International Journal of Advanced Manufacturing Technology 87(5-8): 2195-2211. DOI: 10.1007/s00170016-8542-3

22. Ikushima, K., and Shibahara, M. 2014. Prediction of residual stresses in multi-pass welded joint using idealized explicit FEM accelerated by a GPU. Computational Materials Science 93: 62-67. DOI: 10.1016/j.commatsci.2014.06.024

23. Huang, H., Chen, J., Blair, C., Wang, H. P., Crooker, P., Frederick, G., and Feng, Z. 2018. Prediction of residual stresses in a multipass pipe weld by a novel 3D finite element approach. ASME 2018 Pressure Vessels and Piping Conference: PVP2018-85044. DOI: 10.1115/PVP2018-85044

24. Huang, H., Ma, N., Chen, J., Feng, Z., and Murakawa, H. 2020. Toward large-scale simulation of residual stress and distortion in wire and arc additive manufacturing. Additive Manufacturing 34: 101248. DOI: 10.1016/j.addma.2020.101248

25. Simulia. 2013. Abaqus User's Manual, version 6.13. Dassault Systèmes Simulia Corp. Providence, R.I.

26. Cai, Y., Li, G., Wang, H., Zheng, G., and Lin, S. 2012. Development of parallel explicit finite element sheet forming simulation system based on GPU architecture. Adv. Eng. Softw. 45(1):

370-379. DOI: 10.1016/j.advengsoft. 2011.10.014

27. Bartezzaghi, A., Cremonesi, M., Parolini, N., and Perego, U. 2015. An explicit dynamics GPU structural solver for thin shell finite elements. Computers \& Structures 154: 29-40. DOI: 10.1016/ j.compstruc.2015.03.005

28. Jung, D. W. 1998. Study of dynamic explicit analysis in sheet metal forming processes using faster punch velocity and mass scaling scheme. J. Mater. Eng. Perform 7(4): 479-490. DOI: $10.1361 / 105994998770347620$
29. Olovsson, L., Simonsson, K., and Unosson, M. 2005. Selective mass scaling for explicit finite element analyses. Int. J. Numer. Methods Eng. 63(10): 1436-1445. DOI: 10.1002/nme.1293

30. Kirk, D. 2007. NVIDIA CUDA software and GPU parallel computing architecture. $6^{\text {th }}$ International Symposium on Memory Management: 103-104.

31. Ruetsch, G., and Fatica, M. 2013. CUDA Fortran for scientists and engineers: Best practices for efficient CUDA Fortran programming. Elsevier.

32. Mohammadpour, M., Yazdian, N., Yang, G., Wang, H. P., Carlson, B., and Kovacevic, R. 2018. Effect of dual laser beam on dissimilar welding-brazing of aluminum to galvanized steel. Optics \& Laser Technology 98: 214-228. DOI: 10.1016/j.optlastec.2017.07. 035

33. Goldak, J., Chakravarti, A., and Bibby, M. 1984. A new finite element model for welding heat sources. Metallurgical and Materials Transactions B 15(2): 299-305. DOI: 0.1007/BF02667333

34. Chen, J., Chen, G., Yu, X., Feng, Z., and Crooker, P. 2015. Effect of strain hardening constitutive relations on weld residual stress simulation of dissimilar metal weld. ASME 2015 Pressure Vessels and Piping Conference: PVP2015-45776. DOI: 10.1115/ PVP2015-45748

35. Bang, I. W., Son, Y. P., Oh, K. H., Kim, Y. P., and Kim, W. S. 2002. Numerical simulation of sleeve repair welding of in-service gas pipelines. Welding Journal 81(12): 273-s to 282-s.

36. Bouchard, P. J., George, D., Santisteban, J. R., Bruno, G., Dutta, M., Edwards, L., Kingston, E., and Smith, D. J. 2005. Measurement of the residual stresses in a stainless steel pipe girth weld containing long and short repairs. International Journal of Pressure Vessels and Piping 82(4): 299-310. DOI: 10.1016/j.ijpvp.2004.08.008

37. Gandy, D. W., Findlan, S. J., and Viswanathan, R. 2001. Weld repair of steam turbine casings and piping - An industry survey. J. Pressure Vessel Technol. 123(2): 157-160. DOI:

10.1115/1.1285825

38. Jiang, W. C., Wang, B. Y., Gong, J. M., and Tu, S. T. 2011. Finite element analysis of the effect of welding heat input and layer number on residual stress in repair welds for a stainless steel clad plate. Materials \& Design 32(5): 2851-2857. DOI: 10.1016/j.matdes.2010.12.037

39. Charkhi, M., and Akbari, D. 2019. Experimental and numerical investigation of the effects of the pre-heating in the modification of residual stresses in the repair welding process. International Journal of Pressure Vessels and Piping 171: 79-91. DOI: 10.1016/ j.ijpvp.2019.02.006

40. Keppas, L. K., Wimpory, R. C., Katsareas, D. E., and Ohms, C. 2010. Combination of simulation and experiment in designing repair weld strategies: A feasibility study. Nuclear Engineering and Design 240(10): 2897-2906. DOI: 10.1016/j.nucengdes. 2010.05.034

HUI HUANG (huangh@ornl.gov), JAN CHEN, and ZHILI FENG are with the Materials Science and Technology Division, Oak Ridge National Laboratory, Oak Ridge, Tenn. HUI-PING WANG, WAYNE CAI, and BLAIR E. CARLSON are with the GM Global R\&D Center, General Motors Co. LLC, Warren, Mich. 